\title{
Status of Serum and Salivary Levels of Superoxide Dismutase in Type 2 Diabetes Mellitus with Oral Manifestations: A Case Control Study
}

\author{
Medhini Madi ${ }^{1}$, Subhas Babu ${ }^{2}$, Suchetha Kumari ${ }^{3}$, Shishir Shetty ${ }^{4}$, \\ Sonika Achalli ${ }^{1}$, Ananya Madiyal ${ }^{1}$, Manohar Bhat ${ }^{5}$
}

\begin{abstract}
BACKGROUND: Type 2 Diabetes Mellitus is a very well known metabolic disorder that has reached epidemic proportions worldwide. Evidence suggests that oxidative stress increases in Diabetes Mellitus because of the excessive production of reactive oxygen species and an impaired antioxidant defence mechanism. This study estimated, compared and correlated the serum and salivary Superoxide dismutase levels in healthy subjects and subjects with Type 2 Diabetes Mellitus having oral manifestations.

MATERIALS AND METHODS: In this study, serum and salivary Superoxide dismutase levels were estimated in 45 healthy subjects and 45 patients with Type 2 Diabetes Mellitus with oral manifestations.

RESULTS: The mean serum and salivary Superoxide dismutase levels were significantly decreased in subjects with Type 2 Diabetes Mellitus with oral manifestations compared to the healthy subjects. Positive correlation in both healthy and diabetics was observed between serum and salivary samples.

CONCLUSION: This study highlights that the abnormally high levels of oxidative stress in diabetics coupled with simultaneous decline in antioxidant defence mechanism results in complications in Diabetes mellitus. Thus exploring saliva for antioxidant markers that accurately reflect the redox status of the body is worthwhile.
\end{abstract}

KEYWORDS: Type 2 Diabetes Mellitus, Superoxide dismutase, antioxidant

DOI: http://dx.doi.org/10.4314/ejhs.v26i6.4

\section{INTRODUCTION}

Diabetes mellitus (DM) in all its heterogeneity has taken the centre stage as one of the ultimate medical challenges (1). Type 2 DM was first described as a component of metabolic syndrome in 1988. Type 2 DM (formerly known as noninsulin dependent DM) is the most common form of DM characterized by hyperglycemia, insulin resistance and relative insulin deficiency (2).

Antioxidants can be defined as substances whose presence in relatively high concentration significantly inhibits the rate of oxidation of lipids, proteins, carbohydrates and DNA. Antioxidants such as superoxide dismutase (SOD) act as potent electron donors; they donate hydrogen atoms to pair up with unpaired electrons on free radicals. Thus, they convert reactive free radicals into inactive substances (3).

Antioxidants are classified according to their mode of action as preventive and scavenging antioxidants. Preventive antioxidants suppress the formation of free radicals (e.g. enzymes

\footnotetext{
${ }^{1}$ Lecturer, Department of Oral Medicine and Radiology, A.B. Shetty Memorial Institute of Dental Sciences, NITTE University, Deralakatte, Mangalore

${ }^{2}$ Head of the Department, Department of Oral Medicine and Radiology, A.B. Shetty Memorial Institute of Dental Sciences, NITTE University, Deralakatte, Mangalore

${ }^{3}$ Professor, Department of Biochemistry, K. S. Hegde Medical Academy, NITTE University, Deralakatte, Mangalore

${ }^{4}$ Assistant Professor, Department of Oral Medicine and Radiology, Gulf Medical University, Ajman, UAE

${ }^{5}$ Assistant Professor, Department of Public Health Dentistry, K.V.G. Dental College, Sullia, Dakshina Kannada

Corresponding Author: Medhini Madi, Email: medhkat@gmail.com; medhini.madi@gmail.com
} 
such as superoxide dismutase (SOD), catalase (CAT), glutathione reductase (GR), glutathione peroxidase (GPx) and metal ion sequestrators such as albumin, lactoferrin, transferring and haptoglobin). Scavenging (chain-breaking) antioxidants scavenge radicals to inhibit the chain initiation and break chain propagation. They include vitamin $\mathrm{C}$, vitamin $\mathrm{A}$, vitamin $\mathrm{E}$ and uric acid (4)

SOD is a key antioxidant enzyme that dismutates superoxide anion $\left(\mathrm{O}_{2^{-}}\right)$to continuously form $\mathrm{H}_{2} \mathrm{O}_{2}$ and $\mathrm{O}_{2}$ (4). The determination of the oxidative stress and antioxidants sometimes require invasive techniques such as taking blood samples. Exploring saliva for oxidative stress and antioxidant markers that accurately reflect the redox status of the body has great clinical interest (3).

This study was undertaken to estimate the levels of Superoxide dismutase (SOD) in the serum and saliva of patients with type 2 diabetes mellitus with oral manifestations and healthy controls. Further, correlation was also done between the salivary and serum levels of Superoxide dismutase in the study groups.

\section{MATERIALS AND METHODS}

This study was a case control study conducted on subjects reporting to Department of Oral Medicine and Radiology at a Dental Science Institute in South India during 2012-2014. Sample size was determined based on the pilot study performed on 10 individuals in each group; 0.44 was the expected mean difference between the two groups. Sample size estimation was done by finding out the mean difference between two groups and pooled Standard Deviation and applying it to a standard formula to find out the sample size. This resulted in the sample size of 44.42 .

As the sample size denotes, it is the minimum sample to estimate and to calculate for the statistical analysis. We rounded 44.42 into 45 so as to reduce the errors. Sample size of 90 subjects were divided into 2 equal groups of 45 patients each:

Control Group (Group I): 45 healthy subjects without any oral and systemic diseases.

Study Group (Group II): 45 subjects diagnosed clinically with type 2 diabetes mellitus with laboratory investigations for confirmation and with oral manifestations. The study group included subjects who were diagnosed with type 2 diabetes mellitus for more than 5 years.

Convenient sampling technique was used to recruit individuals under the control and the study groups. For both the control and the study groups, strict inclusion criteria were followed. Healthy subjects in the age group of $30-60$ years and without any history of oral and systemic diseases were taken as controls.

Laboratory investigations were carried out to rule out undiagnosed type 2 diabetes mellitus. Subjects included in the Group I were not on any medications and did not have adverse oral habits like smoking, tobacco chewing and alcohol consumption.

The study group consisted of subjects in the age group of $30-60$ years, clinically diagnosed with type 2 diabetes mellitus and confirmed with laboratory investigations. It included patients who were diagnosed with type 2 diabetes mellitus for more than 5 years and under oral hypoglycemic drugs. Subjects with oral manifestations of diabetes mellitus like burning mouth syndrome, candidiasis, dental caries, gingivitis, glossodynia, lichen planus, neurosensory dysesthesias, periodontitis, salivary dysfunction, taste dysfunction and xerostomia were included in the study group.

Subjects with history of any systemic diseases (other than type 2 diabetes mellitus) were excluded from the study. Pregnant and lactating women were also excluded from the study. Patients diagnosed with any malignancies were not included in the study. Subjects who were on any medications other than oral hypoglycemic drugs were excluded. Subjects with any other oral mucosal lesions other than those stated in inclusion criteria were not considered for the study. Those patients who have adverse oral habits like smoking, tobacco chewing and alcohol consumption were omitted from the study. Each patient was thoroughly examined both intra orally and extra orally under artificial light.

\section{Method of collection of data}

\section{Sample collection}

Informed consent was obtained from the patients included in the study. Ethical clearance was obtained from A. B. Shetty Memorial Institute of Dental Sciences Central Ethical Committee (A Constituent Unit of Nitte University) Deralakatte, 
Mangalore - 575018. Detailed case history was recorded along with thorough examination of the oral cavity.

\section{Saliva collection}

All salivary samples were collected from patients 2 hours after food using spit technique. Patients were asked to sit in the dental chair with head tilted forward and instructed not to speak or swallow any saliva. Then, they were instructed to spit in a sterile graduated container every minute for 5-8 minutes. Salivary sample represents whole mouth fluid (Major and minor salivary glands and gingival crevicular fluid).The collected sample was centrifuged at 3000rpm for 10 minutes, and the supernatant was collected and stored at $-20^{\circ} \mathrm{C}$.

\section{Blood collection}

5 millilitre of venous blood was collected from the antecubital vein with syringe and placed in vials. Serum was then extracted and stored at temperature of $-20^{\circ} \mathrm{C}$ in glass vials. The blood was collected into a grey coloured tube containing $20 \mu \mathrm{l}$ fluoride oxalate to prevent clotting of blood and degradation of glucose.

Estimation of Random Blood sugar levels was done by GOD-POD (Glucose oxidase Peroxidase Method) methodology.
GOD-POD (GLUCOSE OXIDASE PEROXIDASE METHOD) METHODOLOGY

\section{Reagent composition}

Glucose R1

4X100 ml/4X250 ml/4X500 ml/8X250 ml

Phosphate buffer, (pH 7.40) :

$100 \mathrm{mmol} / \mathrm{l}$

Phenol :

$10 \mathrm{mmol} / \mathrm{l}$

Glucose R2

4X100 ml/4X250 ml/4X500 ml/8X250 ml

Glucose oxidase :

$>$ or $=10,000 \mathrm{U} / \mathrm{L}$

Peroxidase :

$>$ or $=600 \mathrm{U} / \mathrm{L}$

4-aminoantipyrine :

$270 \mathrm{mmol} / \mathrm{l}$

Glucose standard

1X5ml/2X5ml/2X5ml

Glucose standard concentration :

$100 \mathrm{mg} / \mathrm{dl}$

\section{Preparation and stability of working reagent}

The reagent 2 (R2) was dissolved with the volume of reagent $1(\mathrm{R} 1)$.

\begin{tabular}{|l|c|c|c|}
\hline & Blank & Standard & Sample \\
\hline Working reagent & $1000 \mu \mathrm{l}$ & $1000 \mu \mathrm{l}$ & $1000 \mu \mathrm{l}$ \\
\hline Standard & - & $10 \mu \mathrm{l}$ & - \\
\hline Sample & - & - & $10 \mu \mathrm{l}$ \\
\hline
\end{tabular}

Reagents were mixed and incubated for 10 minutes at $37^{\circ} \mathrm{C}$. The absorbance of standard and sample were measured against reagent blank.

\section{Calculation for end point test}

GLUCOSE CONC. $\mathrm{mg} / \mathrm{dL}=$ Absorbance of sample / Absorbance of standard X 100 (5).

\section{ESTIMATION OF SOD (SUPEROXIDE DISMUTASE) BY NBT (NITROBLUETETRAZOLIUM METHOD) (BEAUCHAMP AND FRIDOVICH METHOD)}

Blood was collected in a purple coloured EDTA [Ethylene diaminetetraacetic acid (the potassium salt or $\mathrm{K}_{2}$ EDTA)] tube.

Procedure- $0.1 \mathrm{ml}$ of salivary filtrate /blood for each sample was analyzed and a corresponding control was maintained. The beakers were named as:-

TEST $[2.5 \mathrm{ml}$ of methionine, $0.3 \mathrm{ml}$ Riboflavin, $0.1 \mathrm{ml} \mathrm{NBT}$ and $0.1 \mathrm{ml}$ of salivary filtrate].

STANDARD $[2.5 \mathrm{ml}$ methionine, $0.3 \mathrm{ml}$ Riboflavin, $0.1 \mathrm{ml} \mathrm{NBT}, 0.1 \mathrm{ml}$ phosphate buffer $0.05 \mathrm{M}(\mathrm{pH} 7.8)]$ and

CONTROL $[2.5 \mathrm{ml}$ Methionine, $0.3 \mathrm{ml}$ riboflavin, $0.1 \mathrm{ml}$ phosphate buffer $0.05 \mathrm{M}(\mathrm{pH}$ 7.8), $0.1 \mathrm{ml}$ salivary filtrate]. They were subjected to illumination for 10 minutes in an illumination chamber lined with aluminum foil and fitted with a $15 \mathrm{~W}$ fluorescent lamp. Following illumination, immediately, the optical density of all the reaction mixtures was read at $560 \mathrm{~nm}$ units for enzyme present in the sample which was expressed as 
$\mathrm{U} / \mathrm{mg}$ protein (saliva) and $\mathrm{U} \mu \mathrm{g} / \mathrm{Hb}$ (serum) $(6,7)$. The serum and salivary samples were analysed using the Systronics spectrophotometer.

\section{Method of analysis}

The data obtained from the study were analyzed using SPSS version 17.0 software. Independent $t$ test was used to compare superoxide dismutase levels in the study and the control groups. Pearson's correlation coefficient was used to correlate the changes in serum and saliva; $\mathrm{P}<0.05$ was considered significant.

\section{RESULT}

\section{Demographic data analysis of the groups Demographic data analysis of Control Group (Group I)}

The mean age in this group was 40.58 years. Females comprised of $48.9 \%$ (22/45) while males comprised of $51.1 \%$ (23/45) (Table 1, Figure 1).

\section{Demographic data analysis of Study Group (Group II)}

The mean age in this group was 47.91 years. Females comprised of $60.0 \%$ (27/45) while males comprised of $40.0 \%$ (18/45) (Table 1 Figure 1). In the study group, among 45 patients with Type 2 diabetes Mellitus, 42 had Dental caries, 39 had Chronic periodontitis, 5 had Gingivitis, 2 had Candidiasis and 1 had Denture stomatitis. Most of the patients showed combinations of two oral manifestations.

The mean Random Blood Sugar level of Control Group (Group I) was $102.71 \mathrm{mg} / \mathrm{dl}$, and the mean Random Blood Sugar level of Study Group (Group II) was $210.91 \mathrm{mg} / \mathrm{dl}$. In the study Group (Group II), 28/45 patients were poorly controlled diabetics, and $17 / 45$ were well controlled diabetics. The mean duration of Type 2 diabetes in Study group (Group II) was 8.73 years.
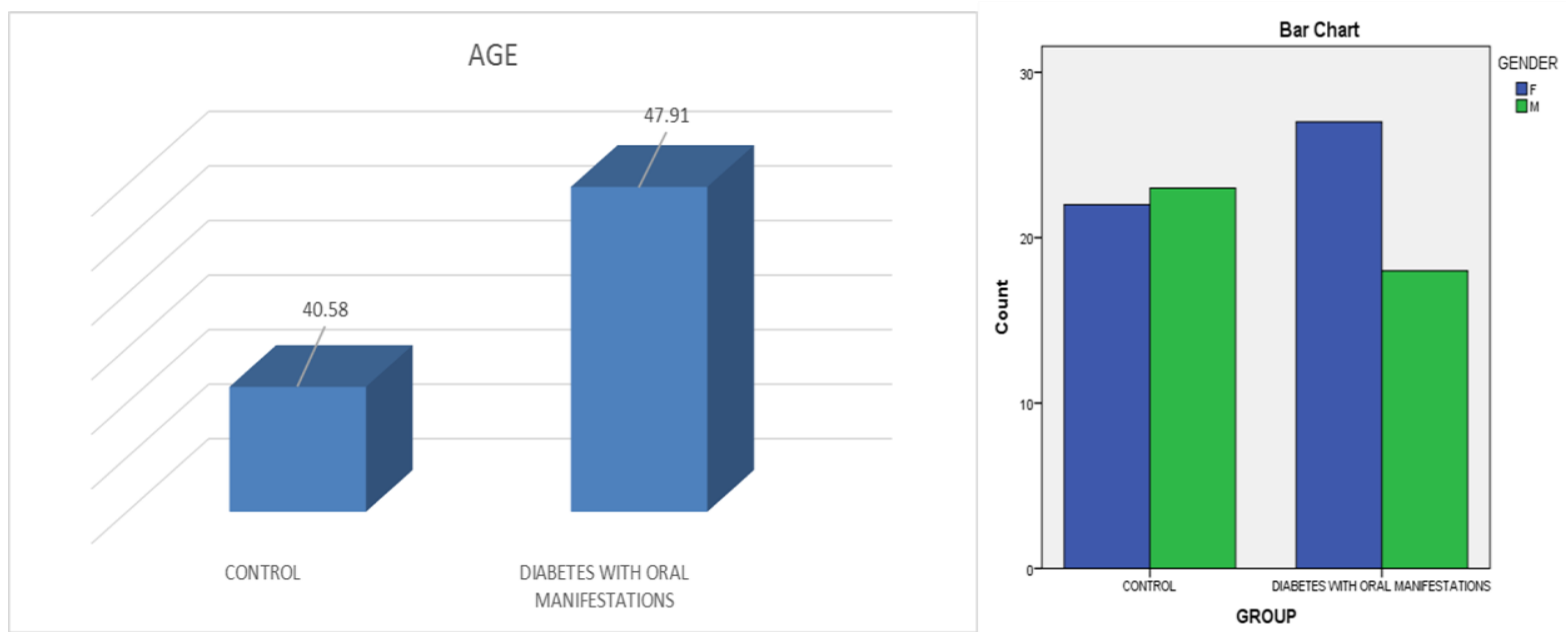

Figure 1: Age and Gender Distribution in Healthy Subjects and Subjects with Type 2 Diabetes Mellitus 
Table 1: Age and Gender Distribution in Healthy Subjects and Subjects With Type 2 Diabetes Mellitus

\begin{tabular}{cccc}
\hline GROUP & N & MEAN AGE & $\begin{array}{c}\text { STANDARD } \\
\text { DEVIATION }\end{array}$ \\
\hline CONTROL & 45 & 40.58 & 7.56 \\
DIABETES WITH & 45 & 47.91 & 7.633 \\
ORAL & & & \\
MANIFESTATIONS & & FEMALE & TOTAL \\
\hline GROUP & MALE & 22 & 45 \\
\hline CONTROL & 23 & 27 & 45 \\
DIABETES WITH & 18 & & 90 \\
ORAL & & 49 & \\
MANIFESTATIONS & 41 & & \\
TOTAL & & &
\end{tabular}

Analysis of mean serum and salivary Superoxide dismutase levels in Controls and Type 2 Diabetics with oral manifestations

\section{Mean Serum Superoxide dismutase levels}

The mean serum Superoxide dismutase level in Group I was $4.315 \mathrm{U} / \mathrm{mg}$ of $\mathrm{Hb}$. The mean serum Superoxide dismutase level of Group II was 2.833 $\mathrm{U} / \mathrm{mg}$ of $\mathrm{Hb}$ (Table 2 Figure 2).

\section{Mean Salivary Superoxide dismutase levels}

The mean salivary Superoxide dismutase level in Group I was $0.169 \mathrm{U} / \mathrm{mg}$ of Protein. The mean salivary Superoxide dismutase levels of Group II was $0.104 \mathrm{U} / \mathrm{mg}$ of Protein (Table 2 Figure 2).

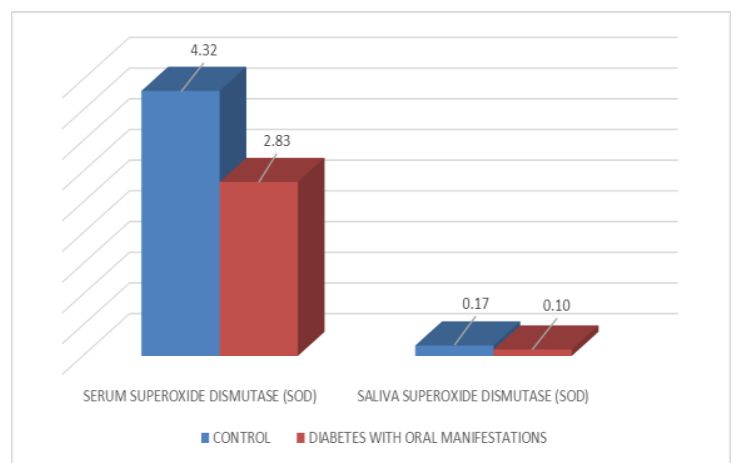

Figure 2: Mean Serum and Salivary Superoxide Dismutase Levels

\section{Analysis of Statistical Significance} Serum and Saliva Superoxide dismutase levels

When serum levels of Superoxide dismutase were compared between Group I (4.315 U/mg of $\mathrm{Hb})$ and Group II (2.833 U/mg of $\mathrm{Hb})$, highly significant differences were obtained $(p<0.001)$ (Table 2). On comparing salivary Superoxide dismutase levels of Group I $(0.169 \mathrm{U} / \mathrm{mg}$ of Protein) and Group II (0.104 U/mg of Protein), the difference was highly significant $(\mathrm{p}<0.001)$ (Table 2). 
Table 2: Comparison of Serum And Saliva Levels of Superoxide Dismutase Using Independent T Test

\begin{tabular}{|c|c|c|c|c|c|c|c|}
\hline & GROUP & $\mathbf{N}$ & MEAN & $\begin{array}{l}\text { STANDARD } \\
\text { DEVIATION }\end{array}$ & $\begin{array}{l}\text { T TEST } \\
\text { VALUE }\end{array}$ & $\begin{array}{c}\text { DEGREES } \\
\text { OF } \\
\text { FREEDOM }\end{array}$ & $\begin{array}{c}\mathbf{P} \\
\text { VALUE }\end{array}$ \\
\hline \multirow[t]{2}{*}{$\begin{array}{c}\text { SERUM } \\
\text { SUPEROXIDE } \\
\text { DISMUTASE } \\
\text { IN U/mg OF } \\
\text { Hb }\end{array}$} & $\begin{array}{c}\text { GROUP } \\
\text { I }\end{array}$ & 45 & 4.3156 & 0.05751 & 42.317 & 49.588 & $<0.001$ \\
\hline & $\begin{array}{c}\text { GROUP } \\
\text { II }\end{array}$ & 45 & 2.8338 & 0.22775 & & & \\
\hline \multirow{2}{*}{$\begin{array}{c}\text { SALIVA } \\
\text { SUPEROXIDE } \\
\text { DISMUTASE } \\
\text { IN U/mg OF } \\
\text { PROTEIN }\end{array}$} & $\underset{\text { I }}{\text { GROUP }}$ & 45 & 0.1698 & 0.02105 & 13.205 & 88 & $<0.001$ \\
\hline & $\begin{array}{c}\text { GROUP } \\
\text { II }\end{array}$ & 45 & 0.1042 & 0.0258 & & & \\
\hline
\end{tabular}

Correlation of Serum Superoxide dismutase with Salivary Superoxide dismutase levels among the two groups

GROUP I: Good positive correlation was observed between serum and salivary Superoxide dismutase levels $(\mathrm{r}=0.412)$ (Table 3 Figure 3 ).

GROUP 2: Very good positive correlation was observed between serum and salivary Superoxide dismutase levels $(\mathrm{r}=0.767)$ (Table 3 Figure 3$)$. 


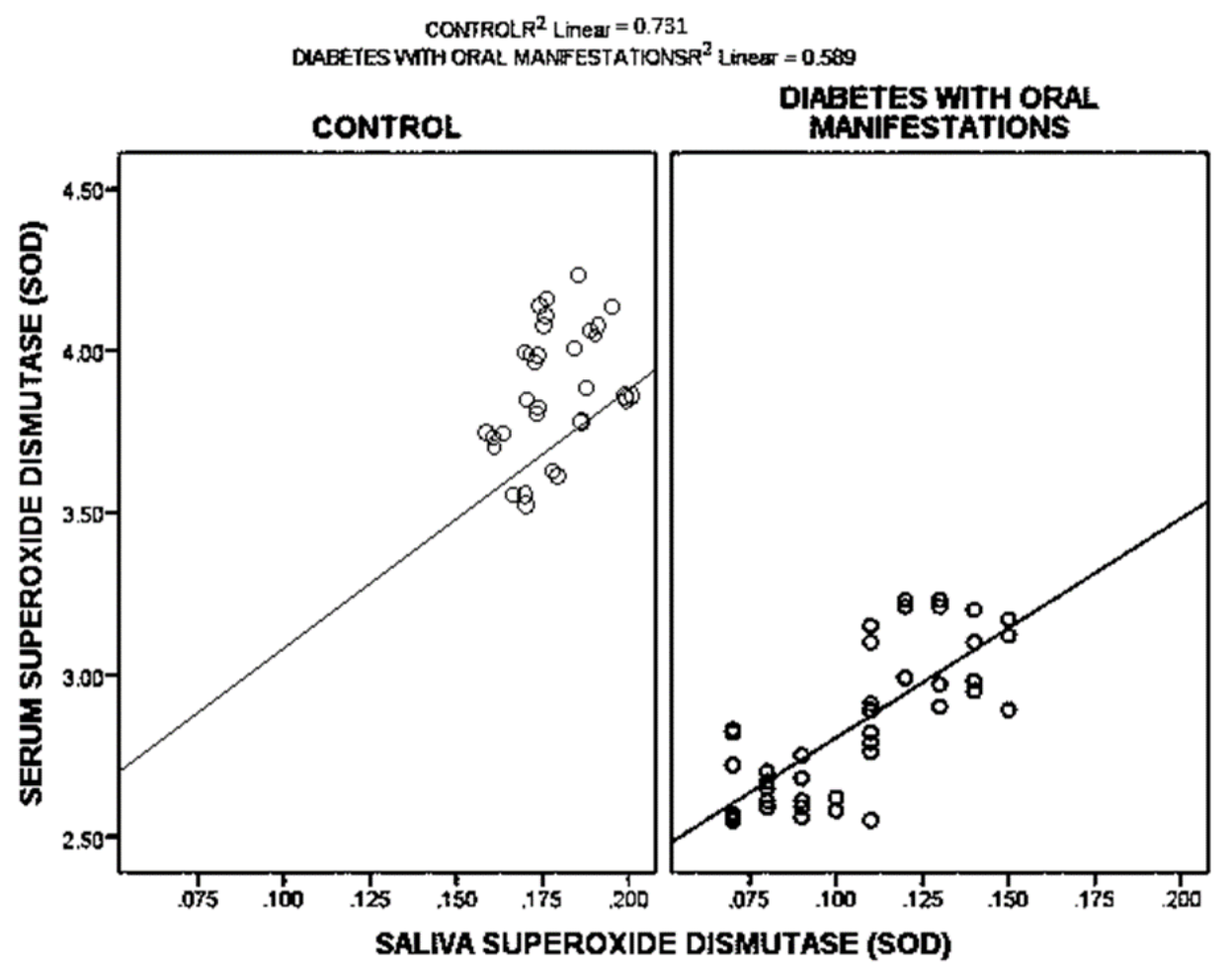

Figure 3: Correlation of Salivary and Serum Levels Using Pearsons Correlation

Table 3: Correlation of Salivary and Serum Levels Using Pearsons Correlation

\begin{tabular}{|c|c|c|c|}
\hline GROUP & & & $\begin{array}{l}\text { SALIVARY } \\
\text { SUPEROXIDE } \\
\text { DISMUTASE } \\
\text { (SOD) }\end{array}$ \\
\hline \multirow[t]{2}{*}{ CONTROL } & $\begin{array}{c}\text { SERUM } \\
\text { SUPEROXIDE } \\
\text { DISMUTASE (SOD) }\end{array}$ & $\begin{array}{c}\text { PEARSONS } \\
\text { CORRELATION }\end{array}$ & 0.412 \\
\hline & & $\begin{array}{c}\text { SIG. (2-TAILED) } \\
\mathrm{N}\end{array}$ & $\begin{array}{c}0.05 \\
45\end{array}$ \\
\hline \multirow[t]{3}{*}{$\begin{array}{c}\text { DIABETES WITH } \\
\text { ORAL } \\
\text { MANIFESTATIONS }\end{array}$} & $\begin{array}{c}\text { SERUM } \\
\text { SUPEROXIDE } \\
\text { DISMUTASE (SOD) }\end{array}$ & $\begin{array}{c}\text { PEARSONS } \\
\text { CORRELATION }\end{array}$ & 0.767 \\
\hline & & SIG. (2-TAILED) & $<0.001$ \\
\hline & & $\mathrm{N}$ & 45 \\
\hline
\end{tabular}




\section{DISCUSSION}

The term diabetes mellitus is derived from the Greek word for "siphon" that means "passing through (urine)", and the word mellitus is derived from Latin, which means "honey". Diabetes mellitus means literally 'honey sweet urine' (8). The incidence of type $2 \mathrm{DM}$ varies substantially from one geographical region to another as a result of environmental and lifestyle risk factors (2).

The rise in the prevalence of Type 2 diabetes mellitus (DM) is viewed as an urban phenomenon with large Indian cities showing four-fold higher rates than rural populations. In contrast, the prevalence of impaired glucose tolerance (IGT) and impaired fasting glycaemia (IFG), considered pre-diabetic, appears to be common in both urban and rural communities. The majority of people with Type $2 \mathrm{DM}$ in developing countries are aged 45-64 years, in contrast to $>65$ years in developed countries. In a recent Indian survey, $56 \%$ of the individuals with Type 2 DM were diagnosed between 40 and 59 years of age and $25 \%$ between 20 and 39 years (9). In our study, the mean age of the patients in the study group consisting of Type 2 diabetics with oral manifestations was 47.91 years.

Abnormally high levels of lipid peroxidation and the simultaneous decline of antioxidant defense mechanisms can lead to damage of cellular organelles and lead to oxidative stress. The antioxidant status of patients may determine whether they develop microvascular or macrovascular complications. Many medical researchers have found that the depletion of body chemicals called antioxidants may increase the risk of complication from diabetes mellitus (10).

An antioxidant can be defined as "any substance that when present in low concentration compared to that of an oxidizable substrate significantly delays or inhibits the oxidation of that substance". Radicals have the capacity to react in an indiscriminate manner leading to damage in almost any cellular component. An extensive range of antioxidant defenses, both endogenous and exogenous, are present to protect cellular components from free radical induced damage (11). Superoxide dismutase (SOD) is widely distributed in oxygen-metabolizing cells and has been supposed to protect such cells against the deleterious action of superoxide radical (12).

In this study, the mean serum Superoxide dismutase level in healthy controls was 4.315 $\mathrm{U} / \mathrm{mg}$ of $\mathrm{Hb}$. However, in subjects with Type 2 diabetes mellitus with oral manifestations, it was reduced to $2.833 \mathrm{U} / \mathrm{mg}$ of $\mathrm{Hb}$ which was significantly lower than the controls. This was in consistent with the studies conducted by Sundaram RK et al (13) and Rahbani-Nobar ME et al (14) where they stated that in diabetic patients, the autoxidation of glucose results in the formation of hydrogen peroxide which inactivates SOD. Therefore, the accumulation of hydrogen peroxide may be one of the explanations for decreased activity of SOD in these patients. The primary catalytic cellular defense that protects cells and tissues against potentially destructive reactions of superoxide radicals and their derivatives is the $\mathrm{Cu} / \mathrm{Zn}-\mathrm{SOD}$. It has been observed that SOD can be rapidly induced in some conditions when cells or organisms are exposed to oxidative stress. The low activity of SOD in diabetes mellitus may suggest that with longer disease duration, SOD induction and consequently its activity progressively decreases. In addition the nonenzymatic glycation which is the other cause for hydrogen peroxide production leads to further inhibition of $\mathrm{Cu} / \mathrm{Zn}$ SOD.

Further, this study is consistent with studies conducted by Taheri E et al (16) and Sayed et al (17) in which the decrease of SOD activity was noticed. This could be attributed to the following reasons:

1. Hyperglycemia activates various biochemical pathways such as glucose autoxidation, nonenzymatic glycation of proteins and activation of protein kinase C. This, in turn, overproduces oxidants like superoxide, hydroxyl radicals and hydrogen peroxide.

2. The increase of glycosylated SOD that leads to the inactivation of this enzyme. (3) Loss of its two factors, $\mathrm{Zn} 2+$ and $\mathrm{Cu} 2+$.

Todate, salivary studies which have been documented in literature are very few. This study showed a significant reduction in SOD in Type 2 Diabetics with oral manifestations when compared to controls. The results are in accordance with the study conducted by Trivedi S et al (4). This study stated that the decreased SOD in the saliva of 
Diabetics might be a consequence of antioxidant depletion. The depletion of the antioxidant is attributable to ongoing free radical activity and breakdown of protective antioxidant species. The reduction in the activitis of SOD may be attributable to excessive oxygen radical production from autooxidation of glucose, glycated proteins and glycation of antioxidative enzymes, which limit their capacity to detoxify oxygen radicals. In the case of Diabetes Mellitus, there is ROS production, but the body is not adapted for the required antioxidant formation. Thus, the level of SOD decreases because of enzymatic use.

In this study, the correlations of Serum Superoxide dismutase with Salivary Superoxide dismutase in the two groups were analyzed. The Pearsons correlation analysis revealed good positive correlation between serum and salivary Superoxide dismutase in healthy subjects $(\mathrm{r}=$ 0.412 ), and very good positive correlation was observed between serum and salivary Superoxide dismutase in subjects with Type 2 Diabetes Mellitus with oral manifestations $(r=0.767)$. Thus, antioxidant parameter assessed in saliva of diabetic patients may be of great importance in evaluating the activity and severity of the disease. The findings of this study suggest the potential role of saliva as an adjunctive tool to monitor prognosis of diabetes mellitus. This study highlights that Type 2 diabetic patients undergo decline of antioxidant defence systems that leads to the development of complications.

In conclusion, saliva could be used as a reliable, non-invasive tool in the assessment of antioxidant levels which may give a substantial insight into the pathogenesis and evolution of diabetes mellitus. Saliva may be a valuable tool in evaluating the progression and severity of diabetes mellitus.

Further extensive studies are required to be conducted with larger samples along with antioxidant therapy. This will help in establishing the reliability of Superoxide dismutase in saliva as a potential biomarker of oxidative stress in diabetes mellitus. Further, it may also help in establishing the role of oxidative stress in the pathogenesis of diabetes mellitus and its complications.

\section{REFERENCES}

1. Srivatsan R, Das $\mathrm{S}$, Gadde R, Kumar KM, Taduri S, Rao N, Ramesh Baharani A, Shah K, Kamireddy SC, Priyatham G, Balakumaran TA, Seshadri S, Kamath A, Rao A. Antioxidants and lipid peroxidation status in diabetic patients with and without complications. Arch Iranian Med. 2009; 12: $121-127$.

2. Olokoba AB, Obateru OA, Olokoba LB. Type 2 Diabetes Mellitus : A review of current trends. Oman Med J. 2012; 28(4):269-273.

3. Rawi NHA. Oxidative stress, antioxidant status and lipid profile in the saliva of type 2 diabetics. Diab Vasc Dis Res. 2011; 8: 22-28.

4. Trivedi S, Lal N, Mahdi AA, Mittal M, Singh B, Pandey S. Evaluation of Antioxidant Enzymes Activity and Malondialdehyde Levels in Patients With Chronic Periodontitis and Diabetes Mellitus. J Periodontol. 2014; 85(5): 713-720.

5. Trinder P, Ann Cain. Biochem 1969;6:24.

6. Beaurchamp, C. and Fridovich, . Superoxide dismutase improved assay applicable to acrylamide gels. Anal. Biochem. 1971;44:276287.

7. Sun Y, Oberly LW and Li YA.A sample method for clinical assay of superoxide dismutase. Clin. chem. 1988;34:497-500.

8. Javed F. Oral inflammatory conditions and diabetes mellitus. Thesis at Karolinska Instituetet; Stockholm. 2008.

9. Raghupathy P, Belavendra A, Caroline H.D, Finney S, Geethanjali, Samantha D. L, Saperia J, Priya G, Abel R, Richard J. High prevalence of glucose intolerance even among young adults in south India. Diabetes Res Clin Pract. 2007; 77: 269-279.

10. Kolhe SM, Khanwelkar CC. Oxidative stress, Antioxidants and Metformin in type 2 diabetes mellitus. Journal of Medical Education and Research. 2013;3(2):25-32.

11. Young IS, Woodside JV. Antioxidants in health and disease. $J$ Clin Pathol. 2001;54:176-186.

12. Misra HP, Fridovich I. The generation of superoxide radical during the autoxidation of hemoglobin. J Biol Chem.1972;247(21):696062. 
13. Sundaram RK, Bhaskar A, Vijayalingam S, Vishwanathan M, Mohan R, Shanmugasundaram KR. Antioxidant status and lipid peroxidation in type II diabetes mellitus with and without complications. Clin. Sci. 1996;90:255-260.

14. Rahbani-Nobar ME, Rahimi-Pour A, RahbaniNobar M, Adi-Beig F, Mirhashemi SM. Total antioxidant capacity, superoxide dismutase and glutathione peroxidase in diabetic patients. Med J Islamic World Acad Sci. 1999;12(4):109-114.

15. Taheri E, Djalali M, Saedisomeolia A, Moghadam AM, Djazayeri A, Qorbani M. The relationship between the activates of antioxidant enzymes in red blood cells and body mass index in Iranian type 2 diabetes and healthy subjects. $J$ Diabetes Metab Disord. 2012;11:3.

16. Sayed AA, Aldebasi Y, Abd-allah SO, Gendy SME, Mohamed AS, Abd El-Fattah MS. Molecular and biochemical study of superoxide dismutase gene polymorphisms in Egyptian patients with type 2 diabetes mellitus with and without retinopathy. $\mathrm{Br} \mathrm{J}$ Med Med Res. 2013; 3(4):1258-1270. 